\title{
Patient-derived orthotopic xenograft glioma models fail to replicate the magnetic resonance imaging features of the original patient tumor
}

\author{
WEI XUE ${ }^{1 *}$, HAIPENG TON $^{1 *}$, JUNFENG ZHANG $^{1}$, TIAN XIE $^{1}$, XIAO CHEN $^{1}$, BO ZHOU $^{1}$, \\ YU GUO ${ }^{1}$, JINGQIN FANG ${ }^{1}$, SHUNAN WANG ${ }^{1}$ and WEIGUO ZHANG ${ }^{1,2}$ \\ ${ }^{1}$ Department of Radiology, Daping Hospital, Army Medical University, \\ ${ }^{2}$ Chongqing Clinical Research Centre of Imaging and Nuclear Medicine, Chongqing 400042, P.R. China
}

Received September 10, 2019; Accepted February 12, 2020

DOI: $10.3892 /$ or.2020.7538

\begin{abstract}
Patient-derived orthotopic glioma xenograft models are important platforms used for pre-clinical research of glioma. In the present study, the diagnostic ability of magnetic resonance imaging (MRI) was examined with regard to the identification of biomarkers obtained from patient-derived glioma xenografts and human tumors. Conventional MRI, diffusion weighted imaging and dynamic contrast-enhanced (DCE)-MRI were used to analyze seven pairs of high grade gliomas with their corresponding xenografts obtained from non-obese diabetic-severe-combined immunodeficiency nude mice. Tumor samples were collected for transcriptome sequencing and histopathological staining, and differentially expressed genes were screened between the original tumors and the corresponding xenografts. Gene Ontology (GO) analysis was performed to predict the functions of these genes. In 6 cases of xenografts with diffuse growth, the degree of enhancement was significantly lower compared with the original tumors. Histopathological staining indicated that the microvascular area and microvascular diameter of the xenografts were significantly lower compared with the original tumors $(\mathrm{P}=0.009$ and $\mathrm{P}=0.007$, respectively). In one case, there was evidence of nodular tumor growth in the mouse. Both MRI and histopathological staining showed a clear demarcation between the transplanted tumors and the normal brain tissues. The relative apparent diffusion coefficient values of the 7 cases examined were significantly higher compared
\end{abstract}

Correspondence to: Professor Weiguo Zhang, Department of Radiology, Daping Hospital, Army Medical University, 10 Changjiangzhilu Road, Chongqing 400042, P.R. China E-mail: wgzhang01@163.com

*Contributed equally

Key words: glioma, dynamic contrast-enhanced-magnetic resonance imaging, diffusion weighted imaging-magnetic resonance imaging, patient-derived xenograft with the corresponding original tumors $(\mathrm{P}=0.001)$ and transfer coefficient values derived from DCE-MRI of the tumor area was significantly lower compared with the original tumors $(\mathrm{P}=0.016)$. GO analysis indicated that the expression levels of extracellular matrix-associated genes, angiogenesis-associated genes and immune function-associated genes in the original tumors were higher compared with the corresponding xenografts. In conclusion, the data demonstrated that the MRI features of patient-derived xenograft glioma models in mice were different compared with those of the original patient tumors. Differential gene expression may underlie the differences noted in the MRI features between original tumors and corresponding xenografts. The results of the present study highlight the precautions that should be taken when extrapolating data from patient-derived xenograft studies, and their applicability to humans.

\section{Introduction}

Patient-derived xenograft (PDX) models are valuable tools for preclinical cancer research studies (1). Several studies have reported that patient-derived glioma stem cells (GSCs) maintain the phenotype and genotype characteristics of the original tumors (2-4), and GSC-derived xenografts recapitulate the distinctive cytological hallmarks and diverse histological variants of the original tumors (5). Therefore, PDX glioma models have been considered as reliable tools to explore the biological characteristics, therapeutic response and imaging biomarkers of glioma (6).

Magnetic resonance imaging (MRI) is widely used for clinical diagnosis, monitoring treatment and prognostic evaluation of gliomas (7-9). Conventional MRI, including $\mathrm{T}_{1}$-weighted and $\mathrm{T}_{2}$-weighted imaging provides information on the anatomical structures of tumors and surrounding tissues (10). Diffusion weighted imaging (DWI)-MRI allows for non-invasive evaluation of the random motion of water molecules (11), and the apparent diffusion coefficient (ADC) value quantitatively and accurately reflects the dispersion of water molecules and the density of tumor cells, respectively, thereby providing information on the growth and proliferation of tumor cells (12). 
Dynamic contrast-enhanced (DCE)-MRI technology uses two compartment models to determine the change in the concentration of the contrast agent over time. The transfer coefficient $\left(\mathrm{K}_{\text {trans }}\right)$ derived from DCE-MRI can be used to reflect the permeability of blood vessels, whereas the plasma volume parameter $\left(\mathrm{V}_{\mathrm{p}}\right)$ can be used to reflect plasma volume. Furthermore, the volume fraction of the extravascular extracellular space $\left(\mathrm{V}_{\mathrm{e}}\right)$ can be used to reflect the volume of extracellular space outside of the blood vessel. Finally, the rate transfer coefficient $\left(\mathrm{K}_{\mathrm{ep}}\right)$ can be used to reflect the reflux rate of the contrast agent via the changes in signal intensity of the contrast agent over time in the blood vessels and extravascular spaces $(13,14)$. These MRI features are closely associated with the histological classification and metabolic process of glioma $(15,16)$, which can reflect the molecular characteristics (17) and genotype (18) of this tumor type, and thus provide a reliable basis for individualized diagnosis and treatment (19).

However, whether the MRI features obtained from patient-derived glioma xenograft models, which reflect the biological characteristics and therapeutic response to glioma, are equally applicable to the original human tumors has not been determined, to the best of our knowledge. Therefore, the aim of the present study was to examine the differences noted in the characteristics of conventional MRI, DWI-MRI and DCE-MRI methods between the original tumors and the corresponding patient-derived orthotopic glioma xenografts. The aim of the present study was to provide an experimental basis for the clinical application of xenograft-derived MRI biomarkers.

\section{Materials and methods}

Clinical cases and experimental animals. The subjects recruited for the present study provided informed consent and consent for publication. Consent for involvement of patients without the ability to suitably make their own decisions was provided by their legal guardian. Surgical specimens from 7 patients (referred to as patients 1-7) with primary high-grade glioma who underwent surgery at the Daping Hospital were collected between December 2016 and December 2017. Tumors were graded according to the World Health Organization (WHO) classification of tumors of the nervous system (20). Each tumor specimen was divided into three sections under sterile conditions. The first section was used to extract primary tumor stem cell spheres, which were subsequently used to establish orthotopic xenograft models. The second section was embedded in paraffin for histopathological analysis and the third section was used for transcriptome sequencing. The study involving patients was approved by the Human Research Ethics Committees of Daping Hospital at the Army Medical University (Chongqing, China; approval no. 2014-9).

The xenografts were grown, and MRI was performed on the tumor-bearing mice during the later stages of tumor growth. Tumor tissues were obtained for histopathological staining and transcriptome sequencing. All non-obese diabetic-severe-combined immunodeficiency (NOD-SCID) nude mice used in the present study were purchased from the Department of Experimental Animals (Daping Hospital, Army Medical University). All protocols involving the use of animals were performed according to the International
Principles of Laboratory Animal Care (21) and were approved by the Animal Use Subcommittee of the Daping Hospital at the Army Medical University. Tumor-bearing mice were sacrificed via cervical vertebra dislocation when they exhibited clinical signs that suggested impending death, such as emaciation, weakness or obvious spinal curvature. Confirmation of euthanasia was performed by assessing cardiac arrest and mydriasis. All mice included in the present study exhibited a single tumor, the maximum level of cachexia observed was a body weight loss $\leq 20 \%$ compared with the age-matched controls. The mean diameter of the xenograft was $<1.2 \mathrm{~cm}$ and the maximum diameter was $1.27 \mathrm{~cm}$.

Magnetic resonance scanning and post-processing of patients. MRI scans were performed using a 3.0 Tesla MRI scanner (Magnetom Verio; Siemens AG) with a 16-channel head coil. The conventional MRI included axial and sagittal $\mathrm{T}_{1}$-weighted, and $\mathrm{T}_{2}$-weighted sequences. The sequence parameters were as follows: $\mathrm{T}_{1}$-weighted imaging $\left(\mathrm{T}_{1} \mathrm{WI}\right)$, repetition time (TR)/echo time $(\mathrm{TE})=250 / 2.67 \mathrm{~ms}$, slice thickness $=5 \mathrm{~mm}$, field of view $(F O V)=230 \times 230 \mathrm{~mm} ; \mathrm{T}_{2}$-weighted imaging $\left(\mathrm{T}_{2} \mathrm{WI}\right), \mathrm{TR} / \mathrm{TE}=4,900 / 96 \mathrm{~ms}, \mathrm{SL}=5 \mathrm{~mm}, \mathrm{FOV}=230 \times 230 \mathrm{~mm}$; DWI-MRI:TR $=6,600 \mathrm{~ms}, \mathrm{TE}=100 \mathrm{~ms}, \mathrm{~b}=0,500,1,000 \mathrm{sec} / \mathrm{mm}^{2}$, slice thickness $=5 \mathrm{~mm}$. DCE-MRI was performed as follows: Two sets of $T_{1}$-weighted images were scanned with the $\mathrm{T}_{1}$-vibe sequence $[\mathrm{TR} / \mathrm{TE}=5.08 / 1.74 \mathrm{~ms}, \mathrm{FOV}=260 \times 260 \mathrm{~mm}$, matrix $=138 \times 192$, slice thickness $=5 \mathrm{~mm}$, flip angle $(F A)=2^{\circ}$ and $15^{\circ} \mathrm{J}$ and subsequently 75 consecutive scans were performed using the $\mathrm{T}_{1}$-twist sequence $(\mathrm{TR} / \mathrm{TE}=4.82 / 1.88 \mathrm{~ms}$, matrix $=138 \times 192$, slice thickness $=3.6 \mathrm{~mm}, \mathrm{FOV}=260 \times 260 \mathrm{~mm}$, $\left.\mathrm{FA}=12^{\circ}\right)$ at $5.3 \mathrm{sec}$ intervals. At the 6th phase, $0.1 \mathrm{mmol} / \mathrm{kg}$ gadolinium contrast (Ominscan, GE Healthcare) agent was injected via the elbow vein at a rate of $4 \mathrm{ml} / \mathrm{sec}$.

ADC maps were calculated automatically using a Siemens syngo MR Workstation (version VE36A; Siemens AG) based on DWI-MRI scanning. Subsequently, the ADC value of the tumor was calculated using the hot-spot method (22). A total of five regions of interest (ROIs) with lower ADC values were selected in the tumor area and the ADC values of the contralateral healthy brain tissues were measured. The relative apparent diffusion coefficient (rADC) values were calculated from the ratio of the tumor area to the healthy brain tissue area. The rADC value of the tumor was represented by the average $\mathrm{AADC}$ value of the five ROIs.

The DCE-MRI data were imported into a GE workstation and OmniKinetics software (version 2.0; GE Healthcare) was used for analysis. An Extend-Tofts model was selected as the hemodynamic model (23). The arterial input function (AIF) was calculated by placing an ROI on the middle cerebral artery and the time and signal intensity curve of the brain functions were obtained from the AIF. Subsequently, the software estimated the $\mathrm{K}_{\text {trans }}$ map. Five ROIs with higher $\mathrm{K}_{\text {trans }}$ values were selected in the tumor area and the $\mathrm{K}_{\text {trans }}$ value of the tumor was represented by the average $K_{\text {trans }}$ value of the five ROIs. The MRI data were analyzed by two experienced researchers.

Primary glioma stem-cell spheres culture. Fresh glioma tissue from the $\sim 1 \mathrm{~mm}^{3}$ pieces were digested in papain (Worthington Biochemical Corporation) at $37^{\circ} \mathrm{C}$ for $\sim 15 \mathrm{~min}$, filtered through a $200 \mu \mathrm{m}$ filter and centrifuged at $300 \mathrm{x} \mathrm{g}$ for $3 \mathrm{~min}$ at room 
temperature. The supernatant was discarded and the cells were resuspended in DMEM/F-12 supplemented with N-2, B-27 (all from Gibco; Thermo Fisher Scientific, Inc.), epidermal grow th factor (20 ng/ml; Sigma-Aldrich Merck KGaA) and basic fibroblast growth factor $(20 \mathrm{ng} / \mathrm{ml}$; PeproTech, Inc.) and cultured in an incubator with $5 \% \mathrm{CO}_{2}$ at $37^{\circ} \mathrm{C}(24)$.

Establishment of orthotopic xenograft glioma models. Xenografts were established in the right basal ganglia of NOD-SCID nude mice. The glioma stem cell spheres were digested with trypsin (Gibco; Thermo Fisher Scientific, Inc.) for $3 \mathrm{~min}$ and the supernatant was discarded by centrifugation. The pellet was resuspended in PBS to a density of $\sim 1 \times 10^{4}$ cells $/ \mathrm{ml}$. Following anesthesia with $5 \%$ chloral hydrate $(300 \mathrm{mg} / \mathrm{kg})$, a total $5 \mu \mathrm{l}$ cell suspension was aspirated with a micro-injector and the needle was vertically inserted at $1.8 \mathrm{~mm}$ posterior and $2.2 \mathrm{~mm}$ to the right of the intersection between the midline and the posterior canthus line of the brain in the NOD-SCID nude mice. The needle was initially inserted to a depth of $\sim 3.5 \mathrm{~mm}$ and withdrawn to $0.5 \mathrm{~mm}$ depth. The cell suspension was slowly injected (at $\sim 1 \mu \mathrm{l} / \mathrm{min}$ ) and the needle was withdrawn following $\sim 10$ min of cell transfer. Glioma stem cell spheres form each human glioma tissue were implanted into 5 NOD-SCID nude mice. In total, 35 mice were used in the present study.

Magnetic resonance scanning and post-processing of xenografts. A Bruker 7.0 T MRI scanner for small animals (BioSpec 70/20 USR; Bruker Corporation) was used and MRI was performed during the later stages of xenograft growth. After anesthesia with isoflurane (3\% for induction and $1.5 \%$ for maintenance), tumor bearing mice were fixed in a flat position and scanned in the later phases of tumor growth. The MRI scanning included coronal $\mathrm{T}_{2} \mathrm{WI}$, sagittal $\mathrm{T}_{1} \mathrm{WI}, \mathrm{T}_{1} \mathrm{WI}$ contrast enhanced, DWI-MRI and DCE-MRI. The sequence parameter settings for $\mathrm{T}_{2} \mathrm{~W} 1$ were as follows: Turbo-RARE sequence, repetition time/echo time $=4,000 \mathrm{~ms} / 45 \mathrm{~ms}$, $\mathrm{FOV}=25 \times 25 \mathrm{~mm}$, matrix sizes $=256 \times 256$, slice thicknesses $=0.5 \mathrm{~mm}$. Similarly for $\mathrm{T}_{1} \mathrm{WI}$, the following parameter settings were used: TR/TE=600 ms/14 ms, FOV=25×25 mm, slice thicknesses $=0.5 \mathrm{~mm}$. For DWI, the parameter settings were as follows: $\mathrm{TR} / \mathrm{TE}=3,000 \mathrm{~ms} / 50 \mathrm{~ms}, \mathrm{FOV}=35 \times 35 \mathrm{~mm}$, slice thicknesses $=0.5 \mathrm{~mm}, \mathrm{~b}=0,500,1,000 \mathrm{sec} / \mathrm{mm}^{2}$. Finally, for DCE-MRI the FLASH sequence was used with a repetition time/echo time of $25.0 \mathrm{~ms} / 1.8 \mathrm{~ms}$. In addition, the following settings were used: $\mathrm{FOV}=25 \times 25 \mathrm{~mm}$, matrix sizes $=128 \times 128$, slice thicknesses $=0.5 \mathrm{~mm}$, slices $=5$, and $\mathrm{FA}=5^{\circ} / 15^{\circ} / 20^{\circ} / 30^{\circ}$. FAs of $5^{\circ}, 15^{\circ}, 20^{\circ}$ and $30^{\circ}$ were used to perform pre-contrast scans and subsequently 100 consecutive scans were performed with an FA of $15^{\circ}$. At the 4 th phase, $0.1 \mathrm{mmol} / \mathrm{kg}$ gadolinium contrast agent was administered via tail-vein injection manually within $3 \mathrm{sec}$.

ADC maps were calculated automatically using Bruker image display and processing software (Paravision version 6.0.1; Bruker Corporation) based on DWI-MRI scanning. A total of five ROIs with lower ADC values were selected in the tumor area and the ADC values of the contralateral healthy brain tissues were measured. The rADC values were calculated from the ratio of the tumor area and the healthy brain tissue. The rADC value of the tumor was represented by the average $\mathrm{rADC}$ value of the five ROIs.
Table I. Patient characteristics.

\begin{tabular}{lclcc}
\hline Case no. & Age, year & Sex & Diagnosis & WHO grade \\
\hline 1 & 58 & Male & GBM & IV \\
2 & 48 & Male & GBM & IV \\
3 & 50 & Female & GBM & IV \\
4 & 67 & Male & GBM & IV \\
5 & 48 & Female & AOD & III \\
6 & 57 & Male & GBM & IV \\
7 & 46 & Female & GBM & IV
\end{tabular}

AOD, anaplastic oligodendroglioma; GBM, glioblastoma; WHO, world health organization.

The DCE-MRI data were processed following import into OmniKinetics. The $\mathrm{K}_{\text {trans }}$ maps were calculated following a 'reference region' model proposed by Cárdenas-Rodríguez et al (25), a total of five ROIs with higher $\mathrm{K}_{\text {trans }}$ values were selected in the tumor area and the $\mathrm{K}_{\text {trans }}$ value of the tumor was represented by the average $\mathrm{K}_{\text {trans }}$ values of these five ROIs. The MRI data were analyzed by two experienced radiologist.

Immunohistochemical staining and blood vessel quantification. Hematoxylin and eosin (H\&E) and immunohistochemical staining were performed on surgical specimens and on the corresponding xenograft samples following paraffin embedding, as described previously (26). The antibodies used were raised in rabbits against human CD34 (1:30; cat. no. ab81289; Abcam). The serial sections were prepared at $2 \mu \mathrm{m}$ thickness and were used for immunohistochemical staining following dewaxing in xylene. Antigen retrieval was performed in a boiling EDTA solution ( $\mathrm{pH} \mathrm{9.0)} \mathrm{for} 2.5 \mathrm{~min}$. The sections were washed with PBS following cooling. $\mathrm{H}_{2} \mathrm{O}_{2}(10 \%)$ and goat serum (Beyotime Institute of Biotechnology) were used to block endogenous peroxidase activity and nonspecific antigens, respectively. Each slice was incubated overnight with the corresponding primary antibody at $4^{\circ} \mathrm{C}$. The specimens were washed with PBS and incubated with horseradish peroxidase-conjugated goat anti-rabbit secondary antibodies at $37^{\circ} \mathrm{C}$ for $30 \mathrm{~min}$. 3, 3'-diaminobenzidine was used to visualize the antigen signal.

A total of five ROIs were selected using the hot-spot method. The images were visualized by light microscopy with x200 magnification. The number, diameters and areas of the CD34-positive lumens were measured, and the average values were used as the tumor microvascular density, diameter and area, respectively. All pathological data for the tissues were measured by two highly experienced staff members who were blinded to the experimental groups.

Transcriptome sequencing and screening of differentially expressed genes. The original tumors (patient tumors 1,2 and 3) and the corresponding xenografts (xenografts 1,2 and 3) were collected for transcriptome sequencing (Wuhan Seqhealth). The differences in mRNA expression levels between the original tumors and the xenografts were compared. Total 

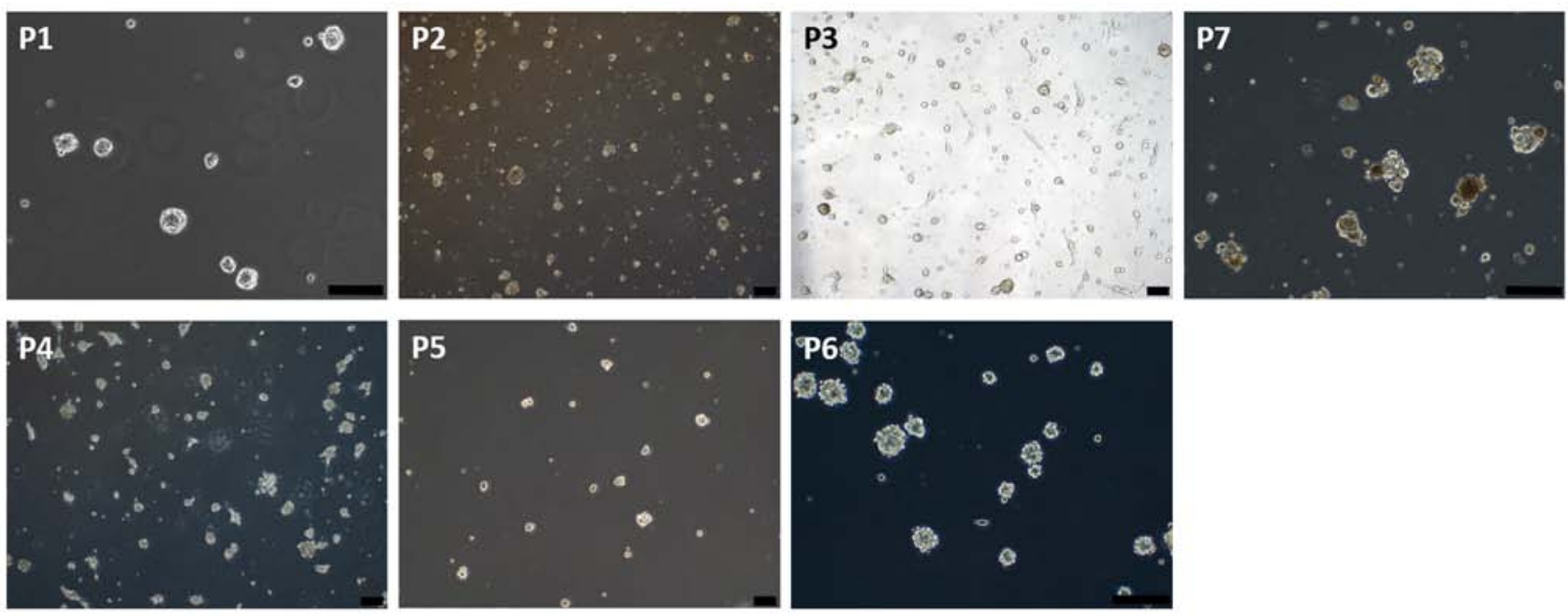

Figure 1. Glioma stem cell spheres were extracted from 7 patients with high grade glioma. Scale bar, $200 \mu \mathrm{m}$. P, patient.

RNA was extracted from the glioma tissues using TRIzol ${ }^{\circledR}$ reagent (Invitrogen; Thermo Fisher Scientific, Inc.). Following removal of the ribosomal RNA and double-stranded RNA, the mRNA was reverse-transcribed into double-stranded cDNA. Polymerase chain reaction (PCR) was performed to amplify and establish the RNA library, which was assessed for nucleotide purity. Agarose gel electrophoresis was used to exclude severely degraded nucleic acid samples, and subsequently, the concentration of nucleic acids was measured using Qubit 2.0 (Thermo Fisher Scientific, Inc.). Samples with a concentration $>200 \mathrm{ng} / \mu$ l and a total quantity $>0.8 \mathrm{mg}$ were considered as suitable samples. The RNA library was sequenced on an Illumina sequencer (Illumina, Inc.). Gene expression levels were determined by several reads per kilobase per million reads and further processed with sample biological repeat correlation testing. Differentially expressed genes were screened between xenografts and their corresponding original tumors (fold change $>2 ; \mathrm{P}<0.05$ ). Gene Ontology $(\mathrm{GO})(27,28)$ analysis was performed to analyze the functions of the differentially expressed genes.

Statistical analysis. SPSS version 19.0 (IBM, Corp.) was used for statistical analysis. A paired t-test was used to compare differences of rADC, microvessel density, microvessel area and diameter values between original tumors and the corresponding xenografts. A Wilcoxon signed-rank test was used to compare differences of $\mathrm{K}_{\text {trans }}$ values between the original tumors and corresponding xenografts. MRI data and pathological result reproducibility were assessed using intraclass correlation coefficient (ICC). $\mathrm{P}<0.05$ was considered to indicate a statistically significant difference.

\section{Results}

Differences in MRI features between xenografts and original tumors. The 7 glioma patients enrolled in the present study included 6 glioblastoma cases (patients 1, 2, 3, 4, 6 and 7) and 1 anaplastic astrocytoma patient (patient-5) (Table I). Glioma stem cell spheres were extracted from the surgical specimens of the patients (Fig. 1), and the orthotopic glioma xenograft model was successfully established in all NOD-SCID nude mice. The growth pattern of the xenografts were divided into two categories. The first category included 6 cases of tumor with diffuse growth (xenografts 1, 2, 3, 4, 5 and 6), with 5 mice per group. The second category was for the one tumor case with nodular growth (xenograft $7 ; \mathrm{n}=5$ mice).

The differences in the MRI features between xenografts and original tumors are described in Table II. The original tumor samples did not have clear tumor boundaries or evidence of edema around the tumor mass. However, certain tumor specimens (patients 3 and 7) possessed a boundary between the tumor and the normal brain tissue in certain regions. The intra-tumoral signals were heterogeneous and multiple necrosis and cystic degeneration were evident. DWI indicated significant high signal intensity in the tumor area region $\left(b=1,000 \mathrm{sec} / \mathrm{mm}^{2}\right)$. Following gadolinium contrast enhancement, marked annular contrast enhancement was observed. The tumor area indicated apparent annular high signal intensity as determined by the $\mathrm{K}_{\text {trans }}$ map (Fig. 2).

The most significant difference noted in the MRI features between the 6 cases of diffusely grown xenografts and the original tumors was the mild enhancement occurring in the local area of the xenografts. The $\mathrm{k}_{\text {trans }}$ value of the xenografts was significantly lower compared with the original tumors. In addition, the internal signal of the tumor was homogeneous in the absence of edema (Fig. 2). This finding was different when compared with the corresponding signal noted in the original tumors (Fig. 2). A clear demarcation between the xenografts and the normal brain tissue was noted in only one case of tumor nodular growth between the two groups (xenografts and human tumor). This was the major difference in the imaging characteristics between these two groups. In addition, the enhancement degree of the xenografts and the $\mathrm{K}_{\text {trans }}$ value of the tumor area were significantly lower compared with the original tumors (Fig. 3). The $\mathrm{K}_{\text {trans }}$ values of all the xenografts were lower compared with the corresponding values of the original tumors, and the rADC values of all the xenograft samples were higher compared with the corresponding values of the original tumors $(\mathrm{P}=0.016$ and $\mathrm{P}=0.001$, respectively; Figs. 2 and 3; Table III). The measurement results were determined using 
Table II. Differences in the MRI features between xenografts and original tumors.

\begin{tabular}{|c|c|c|c|c|c|}
\hline Case & $\begin{array}{l}\text { Intra-tumoral } \\
\text { signals }\end{array}$ & $\begin{array}{l}\text { Peritumoral } \\
\text { edema }\end{array}$ & $\begin{array}{l}\text { Post-contrast } \\
\text { enhancement }\end{array}$ & $\begin{array}{l}\text { Tumor } \\
\text { boundary }\end{array}$ & $\begin{array}{l}\text { Signal } \\
\text { intensity of } \mathrm{K}_{\text {trans }} \text { map }\end{array}$ \\
\hline $\mathrm{P} 1$ & Heterogeneous & Yes & Marked & Unclear & High \\
\hline $\mathrm{X} 1$ & Homogeneous & No & Mild & Unclear & Low \\
\hline $\mathrm{P} 2$ & Heterogeneous & Yes & Marked & Unclear & High \\
\hline $\mathrm{X} 2$ & Homogeneous & No & Mild & Unclear & Low \\
\hline P3 & Heterogeneous & Yes & Marked & Unclear & High \\
\hline $\mathrm{X} 3$ & Homogeneous & No & Mild & Unclear & Low \\
\hline $\mathrm{P} 4$ & Heterogeneous & Yes & Marked & Unclear & High \\
\hline $\mathrm{X} 4$ & Homogeneous & No & Mild & Unclear & Low \\
\hline P5 & Heterogeneous & Yes & Marked & Unclear & High \\
\hline $\mathrm{X} 5$ & Homogeneous & No & Mild & Unclear & Low \\
\hline P6 & Heterogeneous & Yes & Marked & Unclear & High \\
\hline X6 & Homogeneous & No & Mild & Unclear & Low \\
\hline $\mathrm{P} 7$ & Heterogeneous & Yes & Marked & Unclear & High \\
\hline $\mathrm{X} 7$ & Heterogeneous & Yes & Moderate & Clear & Moderate \\
\hline
\end{tabular}

$\mathrm{P}$, patient, $\mathrm{X}$, xenograft; $\mathrm{K}_{\text {trans }}$, transfer coefficient; MRI, magnetic resonance imaging.

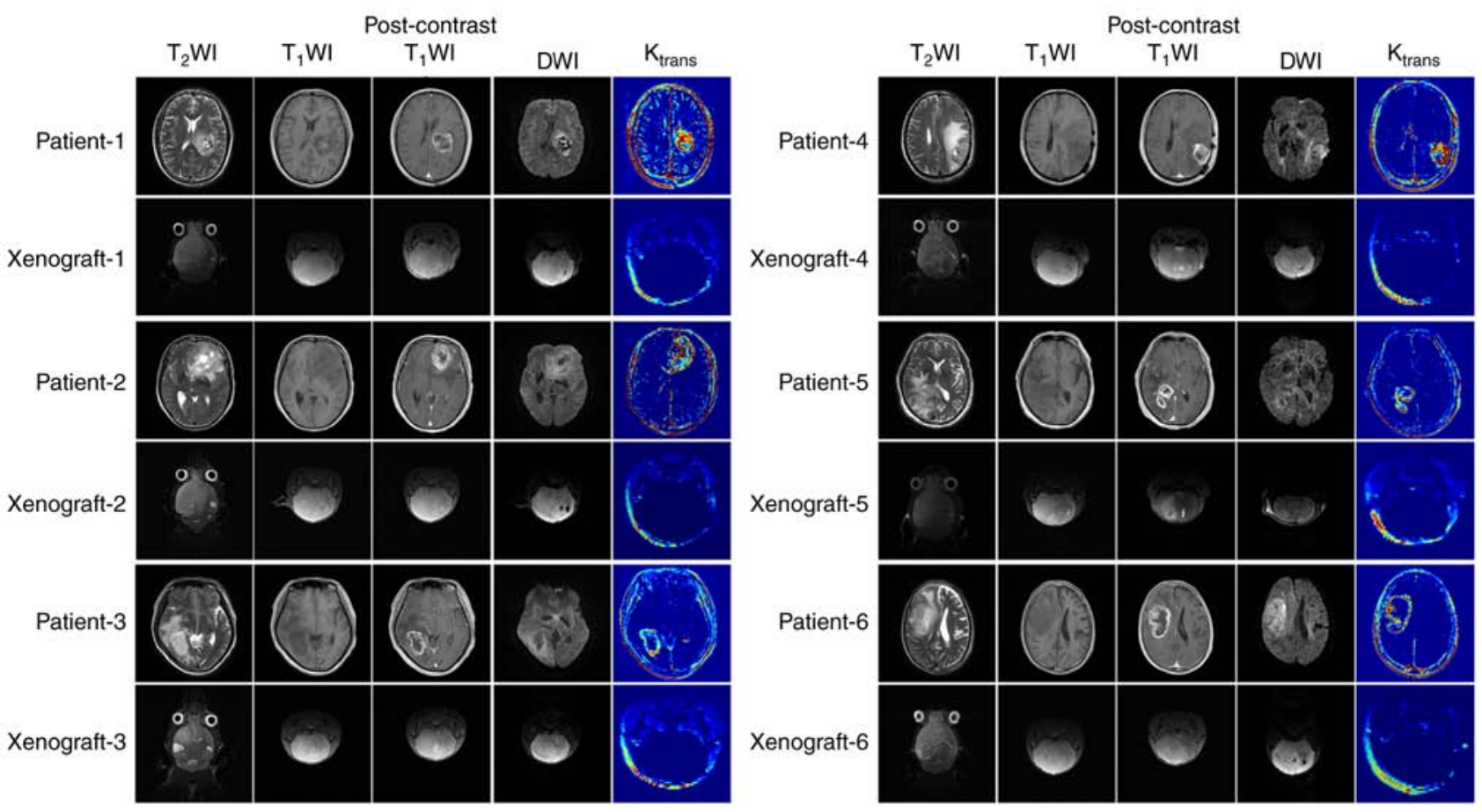

Figure 2. $T_{1} W I, T_{2}$ WI, post-contrast $T_{1} W I$, DWI and $K_{\text {trans }}$ map of xenografts with diffuse growth and of the corresponding original tumors. DWI, Diffusion weighted imaging; $\mathrm{T}_{1} \mathrm{WI}, \mathrm{T}_{1}$-weighted imaging; $\mathrm{T}_{2} \mathrm{WI}, \mathrm{T}_{2}$-weighted imaging; $\mathrm{K}_{\text {trans }}$, transfer coefficient.

the ICC test, a measure of consistency of results, and the ICC value was 0.962 , suggesting the consistency was good.

Among the 6 cases of orthotopic glioma xenograft models with diffuse growth, xenograft-5 was derived from a case of WHO grade III anaplastic astrocytoma, and the rest were derived from glioblastoma. Xenograft 5 showed diffuse growth with a homogeneous internal signal, mild enhancement present in the local area and almost no high signal on the $\mathrm{K}_{\text {trans }}$ map, which were the same as the other xenografts with diffuse growth (Fig. 2). The rADC values of xenograft-5 $(0.948 \pm 0.033)$ were not significantly different from those of other xenografts $(0.937 \pm 0.055)$ with diffuse growth $(\mathrm{P}=0.301)$.

Differences in histopathological features between xenografts and original tumors. $\mathrm{H} \& \mathrm{E}$ staining of the xenografts and human tumor tissues indicated that the boundary of the xenograft tissues was clear, whereas that of the patient tumor was unclear. An example is shown for patient-7 and the corresponding 


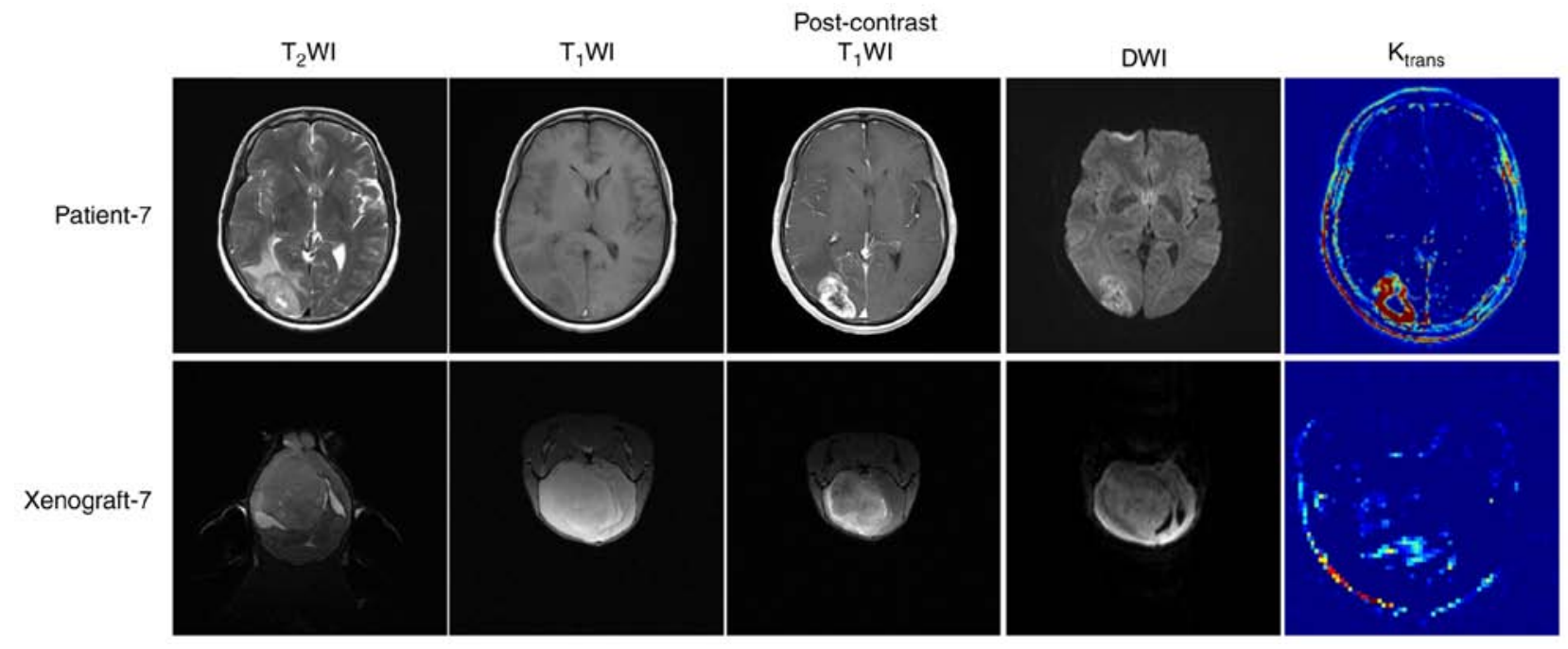

Figure 3. $T_{1}$ WI, $T_{2}$ WI, post-contrast $T_{1}$ WI, DWI and $K_{\text {trans }}$ map of the xenograft with nodular growth and of the corresponding original tumor. DWI, Diffusion weighted imaging; $\mathrm{T}_{1} \mathrm{WI}, \mathrm{T}_{1}$-weighted imaging; $\mathrm{T}_{2} \mathrm{WI}, \mathrm{T}_{2}$-weighted imaging; $\mathrm{K}_{\text {trans }}$, transfer coefficient.

xenograft, where the patient exhibited nodular growth (Fig. 4). However, the tumor boundary was not clear in xenografts with diffuse growth and the corresponding original tumors (Fig. S1). CD34 staining showed that the microvessel area and diameter of the 6 xenograft cases that exhibited diffuse growth were significantly lower compared with the patient tumors $(\mathrm{P}=0.009$ and $\mathrm{P}=0.007$, respectively). There were no significant differences in the microvessel density between the xenografts and the patient tumors (Fig. 5). These findings were verified using an ICC test, with an ICC value of 0.955 .

Differences in gene expression between xenografts and the corresponding original tumors. The differences in gene expression of the samples from patients 1,2 and 3, and the corresponding xenografts are presented in Fig. 6. The black dots between the blue lines represent genes with expression differences $<2$-fold and the red dots represent genes with differences in expression $>2$-fold. The red dots above the blue lines represent genes with higher expression in the original tumors compared with the xenografts, whereas the red dots below the blue lines represent genes with lower expression in the original tumors compared with the xenografts. Significant differences were noted in the gene expression levels between primary tumors and xenografts.

$\mathrm{GO}$ analysis of the differentially expressed genes revealed that tumor cell characteristics and extracellular matrix-associated genes (cell activation, cell adhesion, cell migration, cell motility and extracellular matrix associated genes), angiogenesis-associated genes (angiogenesis and vasculature development) and immune-associated genes (immune response, immune system process and immune effector process) were highly expressed in the original tumors. The expression levels of the genes that were involved in cell cycle and nuclear division were increased in the xenografts (Figs. 7-9).

\section{Discussion}

PDX glioma models are important platforms for assessing the pre-clinical characteristics of tumors. Patient-derived

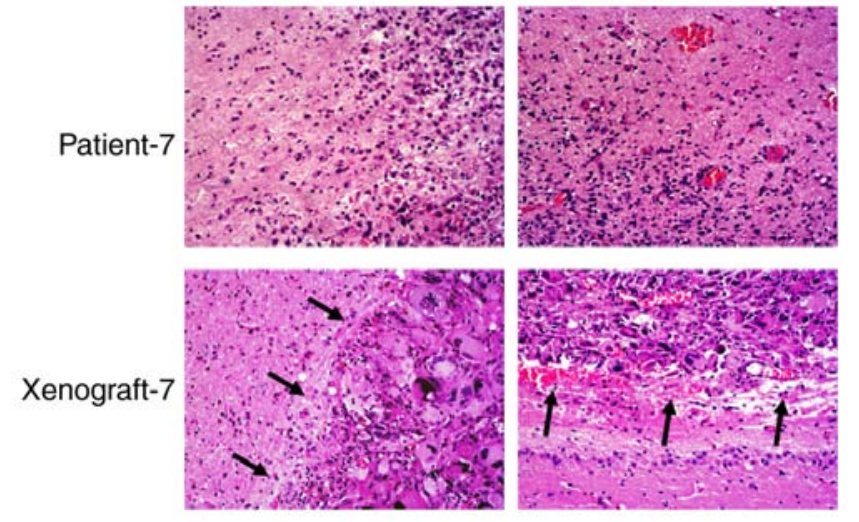

Figure 4. Hematoxylin and eosin staining of the nodular growth of xenografts and the corresponding original tumors. The boundary of xenografts was clear (black arrow), whereas the boundary in the original tumor was unclear.

glioblastoma xenograft models are a reliable translational platform that can recapitulate histopathological properties and maintain the genomic characteristics of parental tumors in situ (29). PDX adamantinomatous craniopharyngioma models recapitulate the radiological features of the original tumors (30).

In the present study, the MRI features of high-grade gliomas and of the corresponding xenografts were considerably different. The primary differences observed in the MRI features between the 6 cases of diffusely grown xenografts and the corresponding original tumors were a mild enhancement in the local area of the xenografts and homogeneous internal signal, and the $\mathrm{K}_{\text {trans }}$ values of the xenografts were significantly lower compared with the original tumors. CD34 staining further demonstrated that the microvessel area and diameter of the 6 cases of diffusely grown xenografts were significantly lower compared with the original patient tumors, consistent with the characteristics of MRI. The MRI characteristics of the nodular xenograft growth samples were compared with those of the corresponding original tumors. A clear demarcation between the xenograft and the normal brain tissues was 
Table III. $\mathrm{K}_{\text {trans }}$ and $\mathrm{rADC}$ values of the original tumors and the corresponding xenografts.

\begin{tabular}{llll}
\hline MRI derived parameters & Original tumors & Xenografts & P-value \\
\hline $\mathrm{k}_{\text {trans }}$ & $1.058 \pm 0.257 \mathrm{~min}^{-1}$ & $0.070 \pm 0.185 \mathrm{~min}^{-1}$ & $0.016^{\mathrm{a}}$ \\
rADC & $0.718 \pm 0.076$ & $0.940 \pm 0.044$ & $0.001^{\mathrm{b}}$ \\
\hline
\end{tabular}

${ }^{\mathrm{a}} \mathrm{P}<0.05,{ }^{\mathrm{b}} \mathrm{P}<0.01$. Data are presented as the mean \pm standard deviation. $\mathrm{K}_{\text {trans }}$, transfer coefficient; $r$ ADC, relative apparent diffusion coefficient; MRI, magnetic resonance imaging.

A

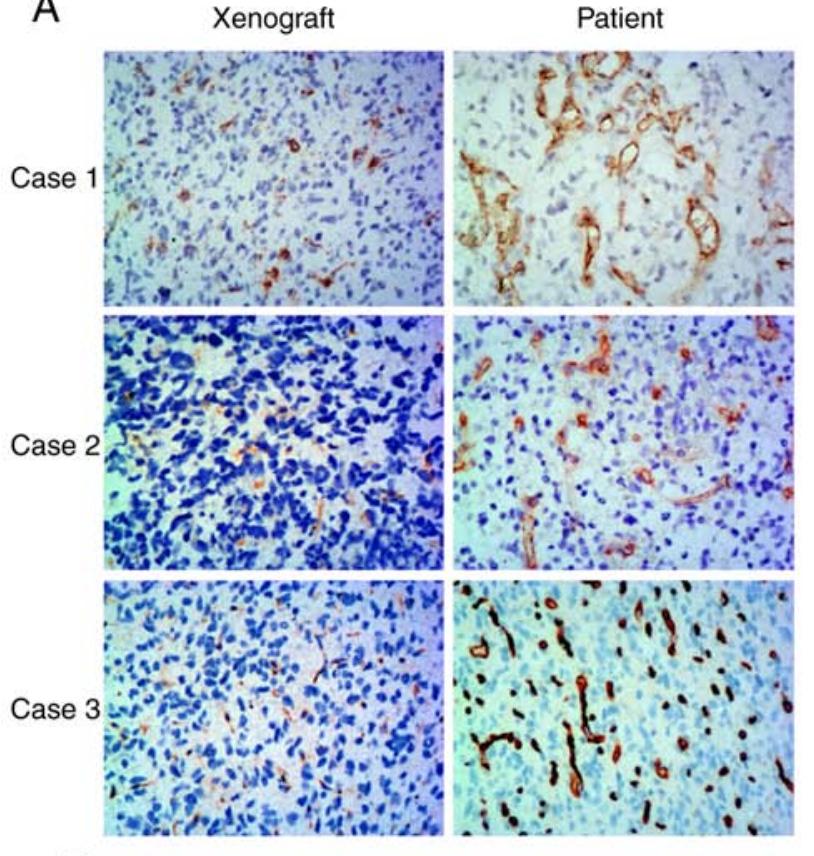

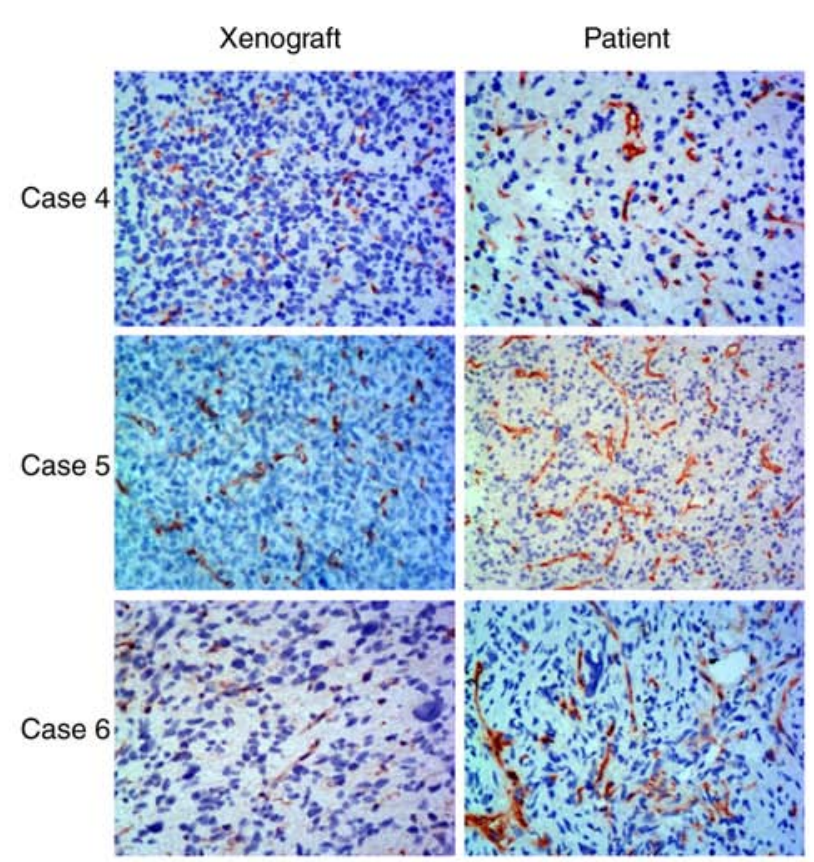

B

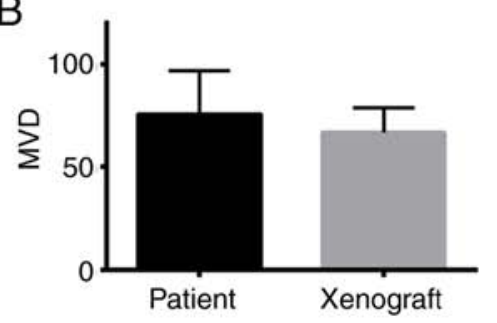

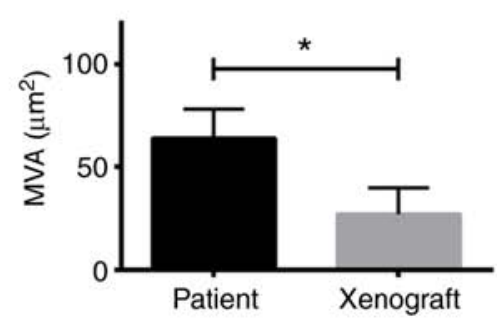

Patient

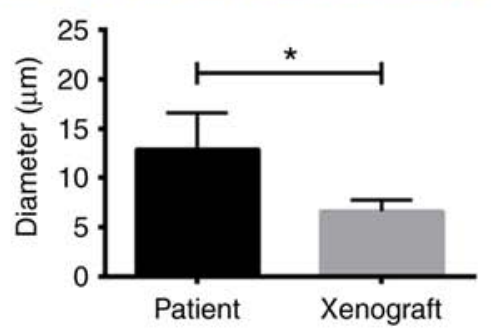

Figure 5. Microvascular analysis of tumor specimens. (A) CD34 immunohistochemical staining of the 6 cases of diffusely grown xenografts and the corresponding original tumors. (B) MVA and diameter of the 6 cases of diffusely grown xenografts were significantly lower compared with the original tumors $(\mathrm{P}=0.009$ and $\mathrm{P}=0.007$, respectively). There was no significant difference in MVD between the xenografts and the original tumors. MVA, microvessel area; MVD, microvessel density.

noted. H\&E staining of the nodular xenograft portion and of the original patient tumor indicated that the boundary of the xenograft was clear, whereas in the original patient tumor, the boundaries were unclear. Although there was only one case with nodular growth, it was reported that gliomas had nodular growth in mice models and had relatively clear boundaries with normal brain tissue (31-33). These results show there were notable differences in the MRI characteristics between patient-derived orthotopic xenograft models and the corresponding original tumors.

The MRI features are closely associated with gene expression. Transcriptome sequencing of the original tumors and their corresponding xenografts revealed significant differences in gene expression. GO analysis of the differentially expressed genes indicated that the expression levels of the immune-associated genes, angiogenesis-associated genes, tumor cell characteristics and extracellular matrix-associated genes were significantly increased in the original tumors. Since certain mesenchymal components in the growth process of xenografts were derived from NOD-SCID nude mice $(34,35)$, the expression levels of immune-associated genes were decreased in the xenografts. The contrast enhancement and increased $\mathrm{K}_{\text {trans }}$ value indicated that the original tumors exhibited significant angiogenic activity and high vascular permeability (36), which may be attributed to the increased expression levels of the angiogenesis-associated 

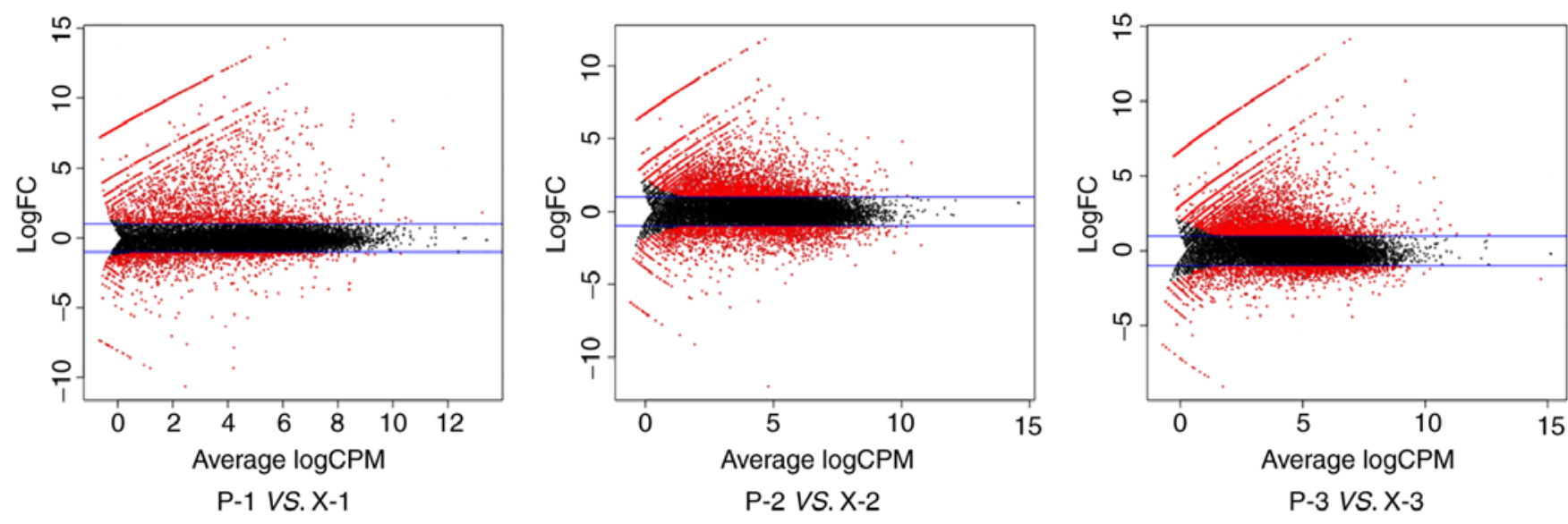

Figure 6. Difference in gene expression levels between patient samples 1,2 and 3, and the corresponding xenografts. The black dots between the blue lines represent genes with expression differences $<2$-fold, whereas the red dots represent genes with expression differences $>2$-fold. The red dots above the blue lines represent genes with higher expression levels in the original tumors than those in the xenografts, whereas the red dots below the blue lines represent genes with lower expression levels in the original tumors than those in the xenografts. P, patient; X, xenograft.
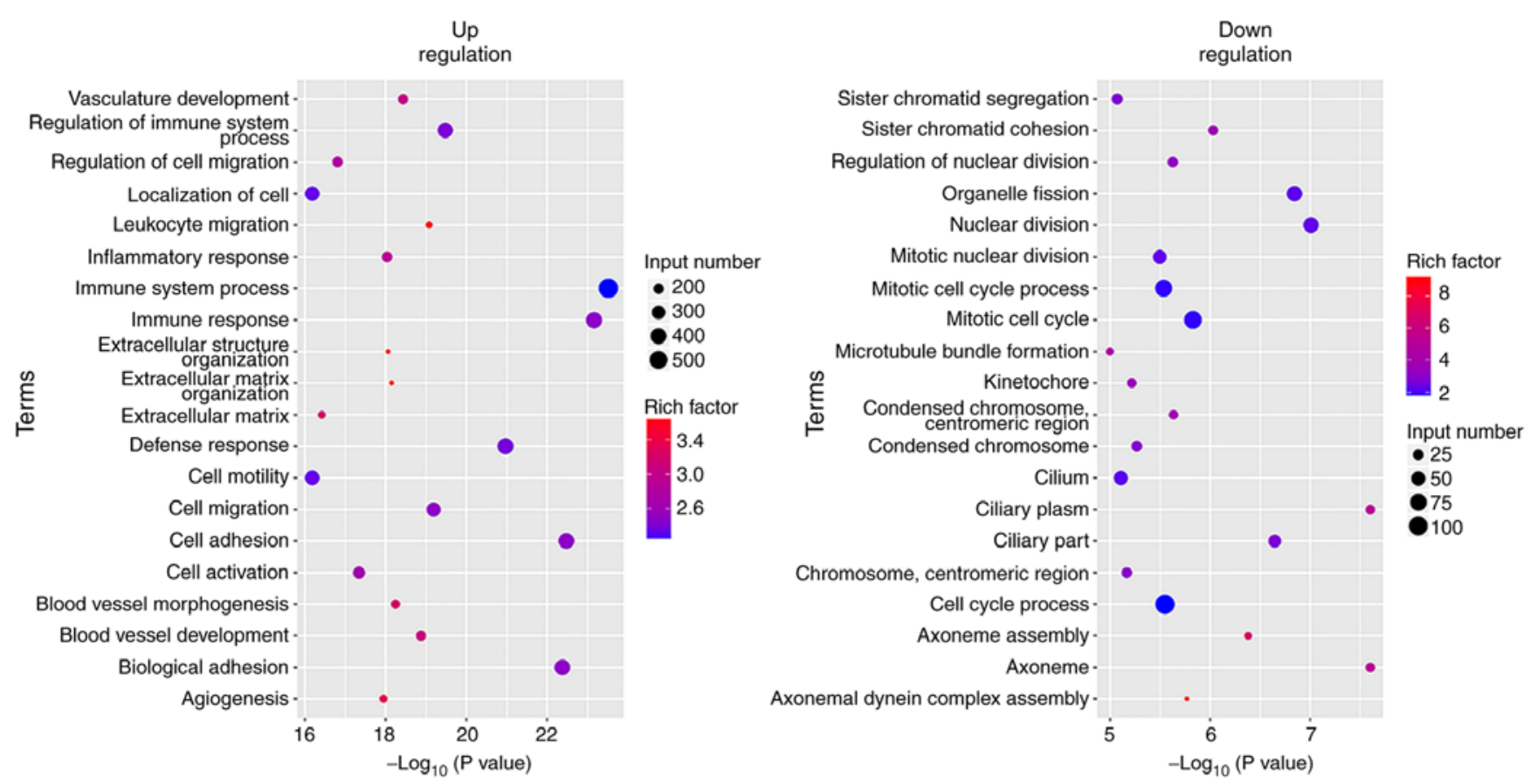

Figure 7. GO analysis of the differentially expressed genes between the original tumor form patient- 1 and the corresponding xenograft. The left column represents GO analysis of genes with higher expression levels in the original tumors compared with the xenografts, whereas the right column represents GO analysis of genes with lower expression levels in the original tumors compared with the xenografts. GO, Gene Ontology; P, patient; X, xenograft; Rich factor; enrichment factor.

genes in the original tumors (37-39). The rADC values of the original tumors were significantly lower compared with the xenografts, which may be attributed with the higher expression levels of the cell adhesion and extracellular matrix-associated genes noted in the original tumors, which in turn resulted in a higher cell density $(40,41)$. Therefore, the differences noted in gene expression levels may underlie the differences noted in the MRI features between the original tumors and the corresponding xenografts.

Although PDX models can maintain the histopathological features and genotypes of the original tumors, the gene expression levels exhibit temporal and spatial heterogeneity and are affected by the tumor microenvironment (42-44). The expression levels of the genes varied according to the different stages of tumor growth and therefore the xenografts assessed may represent only a specific growth stage of the original patient tumor. This may also explain the potent antitumor efficacy of specific treatment strategies on xenografts which are not observed in subsequent human clinical trials $(45,46)$. Therefore, it is particularly important to examine the original patient tumor growth stage when using xenograft models, or to use appropriate tumor models to examine the biological characteristics, therapeutic response and corresponding MRI biomarkers of these tumors. 


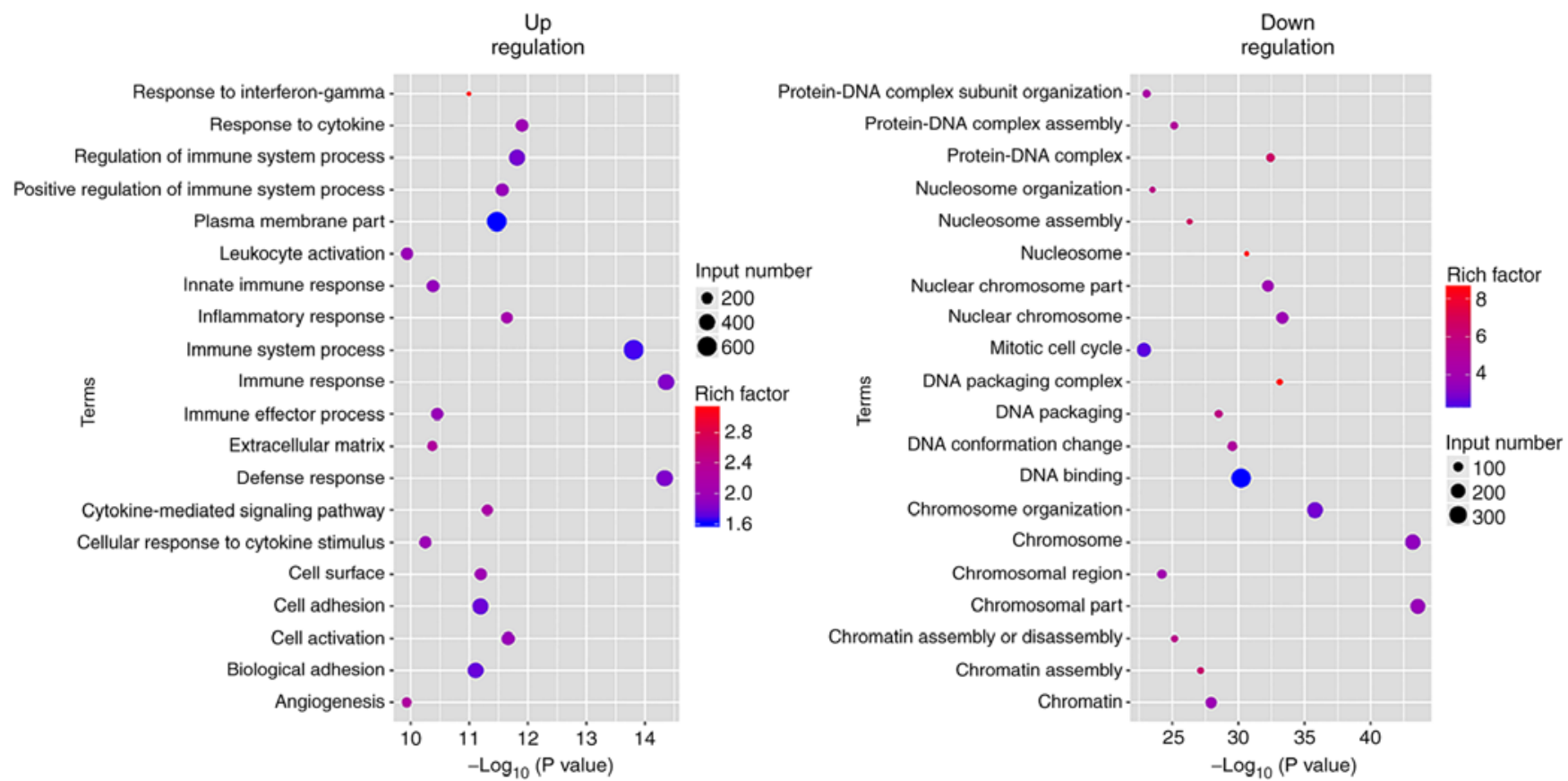

Figure 8. GO analysis of the differentially expressed genes between the original tumor form patient-2 and the corresponding xenograft. The left column represents GO analysis of genes with higher expression levels in the original tumors compared with the xenografts, whereas the right column represents GO analysis of genes with lower expression levels in the original tumors compared with the xenografts. GO, Gene Ontology; P, patient; X, xenograft; Rich factor; enrichment factor.
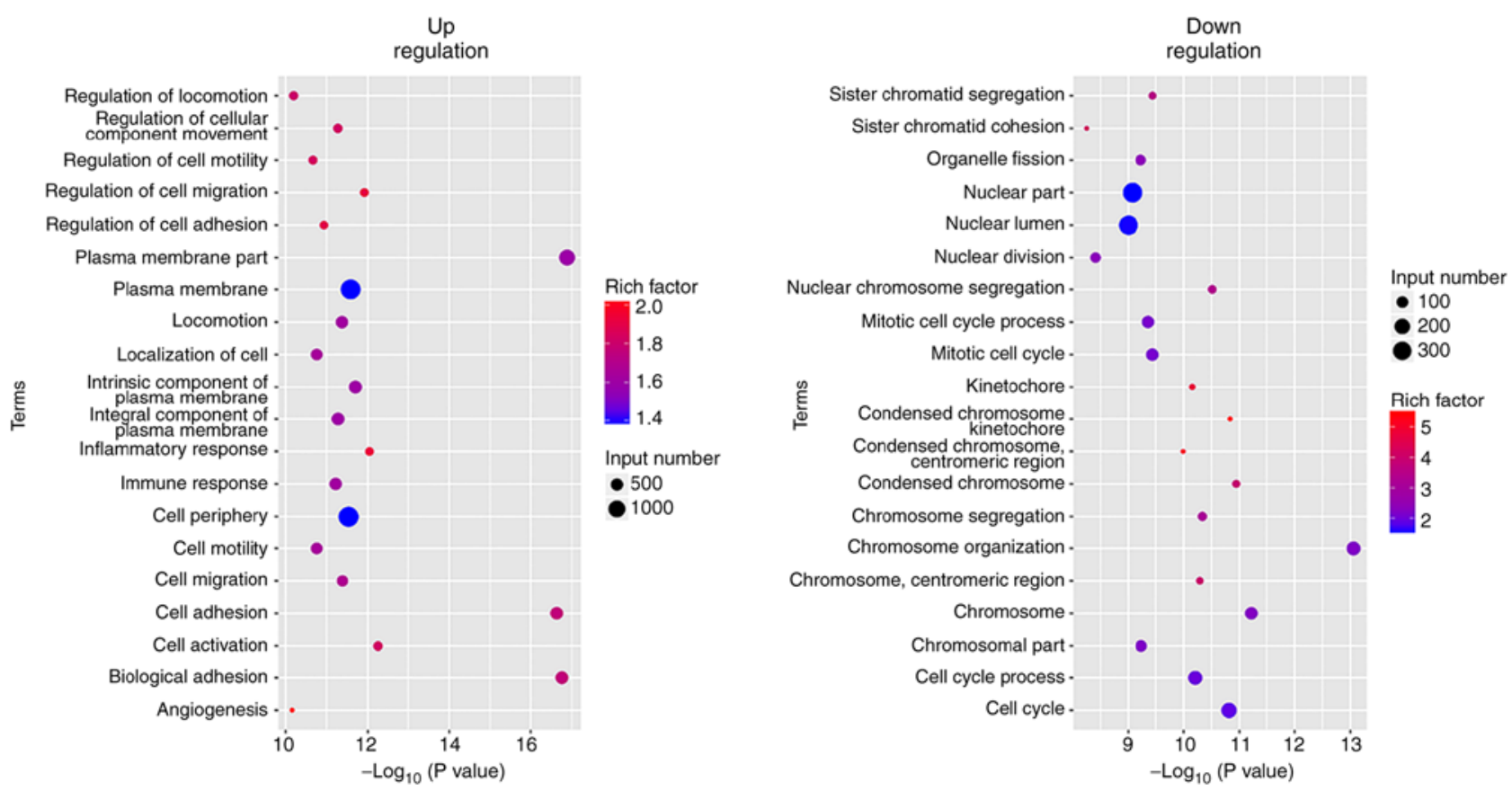

Figure 9. GO analysis of the differentially expressed genes between the original tumor from patient-3 and the corresponding xenograft. The left column represents GO analysis of genes with higher expression levels in original tumors compared with those noted in the xenografts, whereas the right column represents GO analysis of genes with lower expression in original tumors compared with those noted in the xenografts. GO, Gene Ontology; P, patient; X, xenograft; Rich factor; enrichment factor.

The present study has certain limitations. The number of experimental samples was considerably low; thus glioma surgical specimens will continue to be collected to establish and assess more orthotopic xenografts, expanding the sample size, and thus providing additional experimental basis for comparing the similarities and differences between xenografts and the corresponding original tumors. Gene expression between xenografts with nodular growth and the corresponding original tumor should be compared. However, the surgical sample obtained from patient-7 was insufficient. After the extraction of primary tumor cells and histological analysis, the RNA extracted from the remaining tumor tissues failed to pass 
the quality test for establishment of an RNA library; therefore differences in the gene expression of patient-7 and xenograft-7 were not compared. However, there were significant differences in the MRI features between patient-7 and xenograft-7.

Since the tumor microenvironment of nude mice and patients varies, studying the expression differences of GSCs between xenografts and the corresponding original tumors has an important role in preclinical research of gliomas $(47,48)$, for example, this may be the reason why some drugs have notable antitumor effects on animal models $(49,50)$, but did not exhibit a desirable response in clinical trials $(46,51)$, which will be one of the future directions of our lab. The lack of comparison between GSC providers is also one of the limitations of the present study. Analyzing the relationship between MRI characteristics and gene characteristics is of great significance for the accurate diagnosis and personalized treatment of gliomas. Thus, this will be taken into consideration in our future studies.

In summary, the present study demonstrated that patient-derived orthotopic xenograft glioma models in mice could not be used to replicate the MRI features of the original tumors by comparing conventional MRI, DWI-MRI and DCE-MRI characteristics of these two distinct groups. The differential expression of certain genes may underlie the differences observed in the MRI features between original tumors and the corresponding xenografts. Together, the results of the present study showed that MRI biomarkers obtained from PDXs should be interpreted with caution.

\section{Acknowledgements}

Not applicable.

\section{Funding}

The present study was supported by the National Natural Science Foundation of China (grant nos. 81871421 and 81571660) and the Clinical Scientific Foundation of Institute of Surgery Research, Daping Hospital, at the Third Military Medical University (grant no. 2014YLC03).

\section{Availability of data and materials}

All data generated and/or analyzed during this study are available from the corresponding author on reasonable request.

\section{Authors' contributions}

WZ and XC conceived and designed the experiments. WX and $\mathrm{JZ}$ performed the experiments and wrote the first draft of the manuscript. BZ performed clinical case collection. YG performed MRI scanning. JF and SW performed MRI data post-processing and analysis. HT and TX performed the transcriptome sequencing.

\section{Ethics approval and consent to participate}

The present study was approved by the Ethics Committees of the Daping Hospital, at the Army Medical University (Chongqing, China). Written informed consent for participation was obtained from patients and/or their legal guardians.

\section{Patient consent for publication}

Written consent for publication was obtained from patients and/or their legal guardians.

\section{Competing interests}

The authors declare that they have no competing interests.

\section{References}

1. Koga Y and Ochiai A: Systematic review of patient-derived xenograft models for preclinical studies of anti-cancer drugs in solid tumors. Cells 8: pii: E418, 2019.

2. De Witt Hamer PC, Van Tilborg AA, Eijk PP, Sminia P, Troost D, Van Noorden CJ, Ylstra B and Leenstra S: The genomic profile of human malignant glioma is altered early in primary cell culture and preserved in spheroids. Oncogene 27: 2091-2096, 2008.

3. Lee J, Kotliarova S, Kotliarov Y, Li A, Su Q, Donin NM, Pastorino S, Purow BW, Christopher N, Zhang W, et al: Tumor stem cells derived from glioblastomas cultured in bFGF and EGF more closely mirror the phenotype and genotype of primary tumors than do serum-cultured cell lines. Cancer Cell 9: 391-403, 2006.

4. Laks DR, Crisman TJ, Shih MY, Mottahedeh J, Gao F, Sperry J, Garrett MC, Yong WH, Cloughesy TF, Liau LM, et al: Large-scale assessment of the gliomasphere model system. Neuro Oncol 18: 1367-1378, 2016.

5. Wakimoto H, Mohapatra G, Kanai R, Curry WT Jr, Yip S, Nitta M, Patel AP, Barnard ZR, Stemmer-Rachamimov AO, Louis DN, et al: Maintenance of primary tumor phenotype and genotype in glioblastoma stem cells. Neuro Oncol 14: 132-144, 2012.

6. Gargiulo G: Next-generation in vivo modeling of human cancers. Front Oncol 8: 429, 2018.

7. Patel P, Baradaran H, Delgado D, Askin G, Christos P, John Tsiouris A and Gupta A: MR perfusion-weighted imaging in the evaluation of high-grade gliomas after treatment: A systematic review and meta-analysis. Neuro Oncol 19: 118-127, 2017.

8. Suh CH, Kim HS, Jung SC, Choi CG and Kim SJ: Perfusion MRI as a diagnostic biomarker for differentiating glioma from brain metastasis: A systematic review and meta-analysis. Eur Radiol 28: 3819-3831, 2018.

9. Aquino D, Gioppo A, Finocchiaro G, Bruzzone MG and Cuccarini V: MRI in Glioma immunotherapy: Evidence, pitfalls, and perspectives. J Immunol Res 2017: 5813951, 2017.

10. Pope WB and Brandal G: Conventional and advanced magnetic resonance imaging in patients with high-grade glioma. Q J Nucl Med Mol Imaging 62: 239-253, 2018.

11. Minosse S, Marzi S, Piludu F and Vidiri A: Correlation study between DKI and conventional DWI in brain and head and neck tumors. Magn Reson Imaging 42: 114-122, 2017.

12. Sinkus R, Van Beers BE, Vilgrain V, DeSouza N and Waterton JC: Apparent diffusion coefficient from magnetic resonance imaging as a biomarker in oncology drug development. Eur J Cancer 48: 425-431, 2012.

13. Zhang J, Liu H, Tong H, Wang S, Yang Y, Liu G and Zhang W: Clinical applications of contrast-enhanced perfusion MRI techniques in gliomas: Recent advances and current challenges. Contrast Media Mol Imaging 2017: 7064120, 2017.

14. Bernstein JM, Homer JJ and West CM: Dynamic contrast-enhanced magnetic resonance imaging biomarkers in head and neck cancer: Potential to guide treatment? A systematic review. Oral Oncol 50: 963-970, 2014.

15. Guo H, Kang H, Tong H, Du X, Liu H, Tan Y, Yang Y, Wang S and Zhang W: Microvascular characteristics of lower-grade diffuse gliomas: Investigating vessel size imaging for differentiating grades and subtypes. Eur Radiol 29: 1893-1902, 2019.

16. Linnik IV, Scott ML, Holliday KF, Woodhouse N, Waterton JC, O'Connor JP, Barjat H, Liess C, Ulloa J, Young H, et al: Noninvasive tumor hypoxia measurement using magnetic resonance imaging in murine U87 glioma xenografts and in patients with glioblastoma. Magn Reson Med 71: 1854-1862, 2014. 
17. Ahn SS, Shin NY, Chang JH, Kim SH, Kim EH, Kim DW and Lee SK: Prediction of methylguanine methyltransferase promoter methylation in glioblastoma using dynamic contrast-enhanced magnetic resonance and diffusion tensor imaging. J Neurosurg 121: 367-373, 2014.

18. Smits $M$ and van den Bent MJ: Imaging correlates of adult glioma genotypes. Radiology 284: 316-331, 2017.

19. van Dijken BRJ, van Laar PJ, Holtman GA and van der Hoorn A: Diagnostic accuracy of magnetic resonance imaging techniques for treatment response evaluation in patients with high-grade glioma, a systematic review and meta-analysis. Eur Radiol 27: 4129-4144, 2017.

20. Louis DN, Perry A, Reifenberger G, von Deimling A, Figarella-Branger D, Cavenee WK, Ohgaki H, Wiestler OD, Kleihues P and Ellison DW: The 2016 World Health Organization classification of tumors of the central nervous system: A summary. Acta Neuropathol 131: 803-820, 2016

21. Workman P, Aboagye EO, Balkwill F, Balmain A, Bruder G, Chaplin DJ, Double JA, Everitt J, Farningham DA, Glennie MJ, et al: Guidelines for the welfare and use of animals in cancer research. Br J Cancer 102: 1555-1577, 2010.

22. Jackson A, O'Connor JP, Parker GJ and Jayson GC: Imaging tumor vascular heterogeneity and angiogenesis using dynamic contrast-enhanced magnetic resonance imaging. Clin Cancer Res 13: 3449-3459, 2007

23. Sourbron SP and Buckley DL: Classic models for dynamic contrast-enhanced MRI. NMR Biomed 26: 1004-1027, 2013.

24. Pollard SM, Yoshikawa K, Clarke ID, Danovi D, Stricker S, Russell R, Bayani J, Head R, Lee M, Bernstein M, et al: Glioma stem cell lines expanded in adherent culture have tumor-specific phenotypes and are suitable for chemical and genetic screens. Cell Stem Cell 4: 568-580, 2009.

25. Cárdenas-Rodríguez J, Howison CM and Pagel MD: A linear algorithm of the reference region model for DCE-MRI is robust and relaxes requirements for temporal resolution. Magn Reson Imaging 31: 497-507, 2013.

26. Xue W, Du X, Wu H, Liu H, Xie T, Tong H, Chen X, Guo Y and Zhang W: Aberrant glioblastoma neovascularization patterns and their correlation with DCE-MRI-derived parameters following temozolomide and bevacizumab treatment. Sci Rep 7: 13894, 2017.

27. Ashburner M, Ball CA, Blake JA, Botstein D, Butler H, Cherry JM, Davis AP, Dolinski K, Dwight SS, Eppig JT, et al: Gene ontology: Tool for the unification of biology. The Gene Ontology Consortium. Nat Genet 25: 25-29, 2000.

28. The Gene Ontology Consortium: The Gene Ontology Resource: 20 years and still GOing strong. Nucleic Acids Res 47: D330-D338, 2019.

29. Joo KM, Kim J, Jin J, Kim M, Seol HJ, Muradov J, Yang H, Choi YL, Park WY, Kong DS, et al: Patient-specific orthotopic glioblastoma xenograft models recapitulate the histopathology and biology of human glioblastomas in situ. Cell Rep 3: 260-273, 2013.

30. Boult JKR, Apps JR, Hölsken A, Hutchinson JC, Carreno G Danielson LS, Smith LM, Bäuerle T, Buslei R, Buchfelder M, et al: Preclinical transgenic and patient-derived xenograft models recapitulate the radiological features of human adamantinomatous craniopharyngioma. Brain Pathol 28: 475-483, 2018.

31. Wong K, Young GS, Makale M, Hu X, Yildirim N, Cui K, Wong ST and Kesari S: Characterization of a human tumorsphere glioma orthotopic model using magnetic resonance imaging. J Neurooncol 104: 473-481, 2011.

32. Lenting K, Verhaak R, Ter Laan M, Wesseling P and Leenders W: Glioma: Experimental models and reality. Acta Neuropathol 133: 263-282, 2017.

33. Garcia-Romero N, Gonzalez-Tejedo C, Carrión-Navarro J, Esteban-Rubio S, Rackov G, Rodríguez-Fanjul V, Oliver-De La Cruz J, Prat-Acín R, Peris-Celda M, Blesa D, et al: Cancer stem cells from human glioblastoma resemble but do not mimic original tumors after in vitro passaging in serum-free media. Oncotarget 7: 65888-65901, 2016.

34. Xu WW, Li B, Guan XY, Chung SK, Wang Y, Yip YL, Law SY, Chan KT, Lee NP, Chan KW, et al: Cancer cell-secreted IGF2 instigates fibroblasts and bone marrow-derived vascular progenitor cells to promote cancer progression. Nat Commun 8: 14399, 2017.

35. Terai S, Fushida S, Tsukada T, Kinoshita J, Oyama K, Okamoto K, Makino I, Tajima H, Ninomiya I, Fujimura T, et al: Bone marrow derived 'fibrocytes' contribute to tumor proliferation and fibrosis in gastric cancer. Gastric Cancer 18: 306-313, 2015.
36. Hutterer M, Hattingen E, Palm C, Proescholdt MA and Hau P: Current standards and new concepts in MRI and PET response assessment of antiangiogenic therapies in high-grade glioma patients. Neuro Oncol 17: 784-800, 2015.

37. Reyes-Botero G, Dehais C, Idbaih A, Martin-Duverneuil N, Lahutte M, Carpentier C, Letouzé E, Chinot O, Loiseau H, Honnorat $\mathrm{J}$, et al: Contrast enhancement in $1 \mathrm{p} / 19 \mathrm{q}$-codeleted anaplastic oligodendrogliomas is associated with $9 \mathrm{p}$ loss, genomic instability, and angiogenic gene expression. Neuro Oncol 16: 662-670, 2014.

38. Liu X, Li Y, Sun Z, Li S, Wang K, Fan X, Liu Y, Wang L, Wang Y and Jiang T: Molecular profiles of tumor contrast enhancement: A radiogenomic analysis in anaplastic gliomas. Cancer Med 7: 4273-4283, 2018

39. Kickingereder P, Wiestler B, Graf M, Heiland S, Schlemmer HP, Wick W, Wick A, Bendszus $M$ and Radbruch A: Evaluation of dynamic contrast-enhanced MRI derived microvascular permeability in recurrent glioblastoma treated with bevacizumab. J Neurooncol 121: 373-380, 2015.

40. Robba T, Chianca V, Albano D, Clementi V, Piana R, Linari A, Comandone A, Regis G, Stratta M, Faletti C and Borrè A: Diffusion-weighted imaging for the cellularity assessment and matrix characterization of soft tissue tumour. Radiol Med 122 871-879, 2017.

41. Schob S, Surov A, Wienke A, Meyer HJ, Spielmann RP and Fiedler E: Correlation Between aquaporin 4 expression and different DWI parameters in grade I meningioma. Mol Imaging Biol 19: 138-142, 2017

42. Tse V, Xu L, Yung YC, Santarelli JG, Juan D, Fabel K, Silverberg G and Harsh G IV: The temporal-spatial expression of VEGF, angiopoietins-1 and 2, and Tie-2 during tumor angiogenesis and their functional correlation with tumor neovascular architecture. Neurol Res 25: 729-738, 2003.

43. Nikbakht H, Panditharatna E, Mikael LG, Li R, Gayden T, Osmond M, Ho CY, Kambhampati M, Hwang EI, Faury D, et al: Spatial and temporal homogeneity of driver mutations in diffuse intrinsic pontine glioma. Nat Commun 7: 11185, 2016.

44. Phillips LM, Zhou X, Cogdell DE, Chua CY, Huisinga A, $\mathrm{R}$ Hess K, Fuller GN and Zhang W: Glioma progression is mediated by an addiction to aberrant IGFBP2 expression and can be blocked using anti-IGFBP2 strategies. J Pathol 239: 355-364, 2016.

45. Gilbert MR, Dignam JJ, Armstrong TS, Wefel JS, Blumenthal DT, Vogelbaum MA, Colman H, Chakravarti A, Pugh S, Won M, et al: A randomized trial of bevacizumab for newly diagnosed glioblastoma. N Engl J Med 370: 699-708, 2014.

46. Schäfer N, Gielen GH, Kebir S, Wieland A, Till A, Mack F, Schaub C, Tzaridis T, Reinartz R, Niessen M, et al: Phase I trial of dovitinib (TKI258) in recurrent glioblastoma. J Cancer Res Clin Oncol 142: 1581-1589, 2016.

47. Baysan M, Woolard K, Bozdag S, Riddick G, Kotliarova S, Cam MC, Belova GI, Ahn S, Zhang W, Song H, et al: Micro-environment causes reversible changes in DNA methylation and mRNA expression profiles in patient-derived glioma stem cells. PLoS One 9: e94045, 2014.

48. Wang D, Li JR, Zhang YH, Chen L, Huang T and Cai YD: Identification of differentially expressed genes between original breast cancer and xenograft using machine learning algorithms. Genes (Basel) 9: pii: E155, 2018

49. Siegelin MD, Raskett CM, Gilbert CA, Ross AH and Altieri DC: Sorafenib exerts anti-glioma activity in vitro and in vivo. Neurosci Lett 478: 165-170, 2010.

50. Yan D, Kowal J, Akkari L, Schuhmacher AJ, Huse JT, West BL and Joyce JA: Inhibition of colony stimulating factor-1 receptor abrogates microenvironment-mediated therapeutic resistance in gliomas. Oncogene 36: 6049-6058, 2017.

51. Galanis E, Anderson SK, Lafky JM, Uhm JH, Giannini C, Kumar SK, Kimlinger TK, Northfelt DW, Flynn PJ, Jaeckle KA, et al: Phase II study of bevacizumab in combination with sorafenib in recurrent glioblastoma (N0776): A north central cancer treatment group trial. Clin Cancer Res 19: 4816-4823, 2013

This work is licensed under a Creative Commons Attribution-NonCommercial-NoDerivatives 4.0 International (CC BY-NC-ND 4.0) License. 